Wien Klin Wochenschr (2020) 132:223

https://doi.org/10.1007/s00508-019-01571-2
Wiener klinische Wochenschrift The Central European Journal of Medicine

\section{Esoterism in medicine}

\author{
Harald H. Sitte · Markus Müller
}

(C) Springer-Verlag GmbH Austria, part of Springer Nature 2019

The Medical University Vienna, founded in 1365 as the medical faculty of the University of Vienna, is among the largest medical schools in the world. Due to its commitment to the triple track of education, research and patient care, research results and their practical application are directly and rapidly fuelled into the teaching of students. Currently around 8000 medical students undertake medical training at the Medical University Vienna. There are 1200 teachers available to them and they constantly strive to deliver cuttingedge, science-based content to their students; content, which is taught in mandatory courses, lectures and elective courses.

Until recently, one of the elective courses featured the subject "homeopathy". In 2018, a group of students filed a petition to remove the elective course and the Rector and Vice Rector for Education supported their concern and withdrew the course from the curriculum on the grounds of a non-scientific, nonevidence-based approach to the issue of homeopathy. One of the student's main concerns was that the content of the elective course on "homeopathy" was a non-critical appraisal of the subject. Since pseudoscientific approaches, quackery and superstition are part of human hope to achieve healing or salvation, it is not possible to simply ignore these beliefs. Furthermore, practitioners of alternative medicine frequently claim the existence of scientific justification for their approaches, despite the absence of actual evidence or even strong evidence for futility. Hence, a group of professors established an elective course, which

H. H. Sitte $(\bowtie)$

Center for Physiology and Pharmacology, Institute of

Pharmacology, Medical University Vienna, Waehringer

Straße 13A, 1090 Vienna, Austria

harald.sitte@meduniwien.ac.at

M. Müller

Medical University Vienna, Spitalgasse 23, 1090 Vienna,

Austria critically examined alternative medicines and other related contents on its scientific plausibility and the existence of any evidence. The professors and their students ascertained whether there was any evidence to be found in any scientific study on the subject, or whether studied ineffectiveness defined the alternative medical practice as prone purely to esoterism.

The results of the small student working groups have been presented in a large, publicly accessible meeting in May 2019, organized by the Alumni club of the Medical University Vienna, with the title "Esoterism in Medicine: Methods, Evidence, Business Model", where the students presented their critical findings both in short lectures as well as in a poster session. This marked the successful starting point for a meaningful and critical interrogation of a subject that should be brought to the students' attention, also at the Medical University Vienna, which is fully committed to teach, practice and comply to evidencebased medicine.

The second, publicly accessible statement of the Medical University Vienna is this open-access publication on "Esoterism in Medicine", which features most of the presenting groups of last year's meeting. We are happy that the students of the small working groups also took up the task to condense their findings in a series of reviews, which are now comprehensively published in this issue of the Wiener Klinische Wochenschrift. We are also particularly grateful for a commentary by our meetings keynote lecturer, Prof. Edzard Ernst, on this matter.

\section{Harald H. Sitte and Markus Müller}

Conflict of interest H.H. Sitte and M. Müller declare that they have no competing interests.

Publisher's Note Springer Nature remains neutral with regard to jurisdictional claims in published maps and institutional affiliations. 